\title{
Taking a Constructional Approach to Language Change
}

Welcome back to Ten Lectures on Diachronic Construction Grammar. In the last lecture, I have presented Construction Grammar as a cognitive approach to linguistic knowledge. In this lecture, I will try to show how these ideas can be applied to the study of language change. As the title of the lecture suggests, I will be taking a constructional approach to language change.

The central question that I want to begin to answer in this lecture is why and how a constructional approach to language change might differ from other ways of studying how language develops over time. What is special about Diachronic Construction Grammar? Why should you be interested in it? Does it allow us to see and understand things that we would not be able to understand otherwise? What are the advantages that a constructional approach can bring us? I want to address these questions by going back to the ten basic ideas of Construction Grammar that I started out with in the previous lecture. The basic ideas that are foundational for Construction Grammar by implication also form the basis for any approach that takes Construction Grammar into the diachronic domain. Idea $\#_{1}$ is that all of linguistic knowledge is a network of form-meaning pairs. For diachrony, this implies that we will be thinking about language change as change in that network of constructions. What happens to the network of constructions when one construction or several constructions change?

Idea $\#_{2}$ is that the basic unit of linguistic knowledge are symbolic formmeaning pairings. That means that speakers today know constructions that are different from the constructions that were used by speakers of earlier generations. Our knowledge of form-meaning pairings is different from the knowledge of speakers that lived generations ago.

Idea \# 3 is the observation that constructions vary in terms of complexity and schematicity. You remember the quote by Langacker that I gave you in that

All original audio-recordings and other supplementary material, such as any hand-outs and powerpoint presentations for the lecture series, have been made available online and are referenced via unique Dor numbers on the website www.figshare.com. They may be accessed via this QR code and the following dynamic link: https://doi.org/10.6o84/mg.figshare.1369o978. 
context. Sociolinguists have been telling us for a long time that variation and change are really two sides of the same coin. One question we can ask with regard to diachrony is how constructions change in terms of complexity and in terms of schematicity. Here we are really entering the realm of questions that have been asked in grammaticalization studies. How does complexity build up in languages? How do highly schematic constructions and syntactic patterns develop? I will talk about these questions.

Idea \# 4 relates to the fact that constructions are often idiosyncratic, unpredictable and riddled with exceptions. How does this unpredictability come about? What about the opposite, that is, the tendency for irregular forms to become regularized through analogy? On average, do constructions become more regular or more irregular as time goes on?

Idea \# 5 is the claim that all constructions carry meaning. For diachrony, this raises the interesting question of how syntactic patterns like the ditransitive construction acquire their meaning historically and what happens to their meaning over time.

Idea \#6 is the principle of coercion, which states that constructional meaning wins out over lexical meaning. From a diachronic perspective, it would be very interesting to investigate when and how a construction starts to bring about coercion effects. When, for example, did it become possible in the English language to turn mass nouns into accountable units via the plural construction? You remember the example Two beers, please.

Idea \#7 states that grammatical categories are the outcome of speakers generalizing over instances of language use. That has strong implications for diachrony as well. Concrete instances of language use, taken from diachronic corpus data, should be able to reflect the emergence and the development of grammatical categories. I have engaged with this idea in my work, and we'll see a number of examples in later lectures.

The same is true for idea \#8, the notion that constructional meaning is reflected in associations between syntactic patterns and lexical elements. By implication, diachronic shifts in such patterns of association should be indicative of semantic change, and this idea has been central to my own research.

Idea \# 9 is that knowledge of constructions is usage-based. This idea has the implication that as new instances of a construction are produced, the representation of that construction changes as well, leading to potentially further uses that then let speakers repeat the cycle. This brings us to the role of diachronic corpus data and the analysis of such data, which will be an important part of the next lectures.

Finally, idea \#10 is that language draws on domain-general social cognitive processes, like categorization or joint attention. If we take that point seriously, 
it means that all language change is due to the cognitive and social pressures that are at work in the here and now. The question is, how do these pressures bring about long-term changes, such as the grammaticalization of constructions? That is a puzzle that I want you to appreciate. There are forces acting on language in the here and now and they have to be the locus of language change. But these changes accumulate to developments that are much longer than the life of a single speaker. How is that possible? How does that work?

The basic ideas of Construction Grammar already provide a rich foundation for the constructional study of language change that makes us see new things and ask new questions. I will come back to these ideas one by one during the next lectures.

Let me start, however, by saying something general about constructions and language change. I have been lucky to be part of a vibrant community of researchers who have been interested in Diachronic Construction Grammar. Over the past ten or so years, more and more work has adopted a constructional perspective on language change. These studies focus on form-meaning pairings and their diachronic developments. The alignment between historical linguistics on the one hand and Constructional Grammar on the other has become increasingly popular, and even though I welcome that development, it has always puzzled me a little bit. Construction Grammar represents a very different tradition than historical linguistics. It adopts a synchronic perspective, it takes a cognitive, mentalist stance, and that is not the case for many historical approaches. Work in language change always goes beyond a steady state. It does not just describe a speaker's knowledge at a certain point in time. Historical linguistics also goes beyond the confines of a single human mind. If we want to talk about regularities and how languages change over decades, centuries, perhaps even millennia, then we are making generalizations that go beyond what happens in any single speaker or any single human mind. Even though I have always been convinced that Diachronic Construction Grammar is a fascinating approach that has its justification, I have found it surprising that it turned out to be as popular as it has. What is so attractive about it?

I can of course only speculate, but the best answer that I can give brings us back to basic idea $\#_{4}$ that I outlined earlier, the observation that constructions are typically unpredictable and idiosyncratic. Nobody, I think, is more aware of the unruliness of language than historical linguists.

Analysts of language change are very much aware that historical developments often are unpredictable and idiosyncratic. In fact, there is a very nice quote by Paul Hopper and Elizabeth Traugott (2003: 131) illustrating that very point. In their textbook on grammaticalization, they state that 
There is nothing deterministic about grammaticalization and unidirectionality. Changes do not have to occur. They do not have to go to completion. In other words, they do not have to move all the way along a cline.

With regard to idiosyncrasies, Hopper and Traugott were construction grammarians all along.

The constructional way of thinking about language resonates with ideas that historical linguists had already entertained, specifically if they were working within a broadly functional framework. For them, it was more or less self-evident that language change is the sum of many constructions changing individually, often in unpredictable ways. This contrasts with structuralist and generative perspectives, in which language change is seen as catastrophic and systemic, so that one change triggers another until the entire system revolves and changes. I refer to the work of Bloomfield (1933) and Lightfoot $(1979,1999)$ in this context.

In contrast to these views, one might actually adopt the opinion that every construction has its own history, which in this strong form is probably not true. It is tempting to think along these lines, but it is perhaps not quite what the constructional view implies. Remember that knowledge of language is conceived of as a network of symbolic units. Due to interconnections in the constructional network, changes in one construction can be thought to bring about changes in related constructions, but how exactly that works is something to be figured out. A more nuanced view of this could be captured by a slogan that I have tried to popularize. What I said was "Grammatical change is not a zero-sum game" (Hilpert 2013:4). When you pinch the system on one end, it does not always extend at the other end, or vice versa. Linguistic systems are fluid and have some tolerance. Changing one part might have consequences, but it is not a zero-sum game. You have to maintain a kind of balance, a system where everything holds itself in place as the structuralist notion has it. Change on the constructional view is not always systemic. One construction's success does not have to come at the price of another's demise, but changes typically relate to one another, and changing constructions influence one another.

Before I work out in more details what a constructional theory of language change looks like, I would like to point out a few issues that such a constructional theory does not cover. Let me tell you what it is not. There are several well-known phenomena in language change that do not, in my view, lend themselves particularly well to a constructional analysis, principally because they systematically affect many or even all constructions of a language. The prime example of such a phenomenon would be regular sound change that affects all words in the language. If you have a change where all long /e:/ vowels 
turn into long /i:/ vowels across all the words of a language, you could describe that across all individual constructions that are affected, but in doing so you would miss the larger generalization that is there.

Another example would be a massive loss of morphology due to language contact. If two languages are coming into contact and large numbers of learners acquire these languages, some of their morphological complexity is going to disappear. That is not something that would be specific to any one or two constructions, but rather, this happens across the board. Another example in English is there has been a syntactic change from head-final to head-initial across different phrase types. Old English used to be head-final in verb phrases and in auxiliary phrases. In Present-Day English, these phrases are head-initial. This development is best accounted for by a generalization that affects more than just one construction.

Another example is sociolinguistic change in response to extralinguistic developments, as for example dialect levelling in areas with increased speaker mobility. What happens to the local variety once speakers are very mobile? These phenomena, I would argue, capture generalizations that hold across many different constructions. We could apply a constructional approach, but we would miss more insightful, broader generalizations.

Diachronic Construction Grammar focuses on the developmental trajectories of individual constructions where this is useful. This of course has been the focus of another theoretical approach to language change, namely grammaticalization theory. I would like to say a few words about that approach.

What is different between Diachronic Construction Grammar and grammaticalization theory? These two frameworks have a lot in common, and they are adopted by overlapping communities of researchers. Nonetheless, I find it useful to consider for a moment how the two frameworks differ from each other and what their respective aims are, because they are not quite identical.

I take it that many of you in this room are broadly familiar with grammaticalization as a theory of how closed-class elements come into being. For my purposes, I adopt the definition of grammaticalization that has been proposed by Paul Hopper and Elizabeth Traugott (2003), who formulate it as

the change whereby lexical items and constructions come in certain linguistic contexts to serve grammatical functions, and, once grammaticalized, continue to develop new grammatical functions.

My understanding of grammaticalization further owes a lot to Christian Lehmann's work. Lehmann (2015: 15) conceives of grammaticalization as a progressive development towards ever more compact linguistic structures. 
Structures that are only loosely connected in discourse become more tightly integrated through syntacticization. Syntactic structures have a tendency to fuse together through morphologization. Morphological structures blend into one another to form synthetic structures. Eventually, parts of these structures may reduce to zero. The general appeal of grammaticalization theory, as I see it, is motivated by two factors. On the one hand, grammaticalization theory states broad empirical generalizations that account for lots of cases across many different languages. On the other hand, it makes testable predictions for data that we may come across in the future. This is already a point that sets grammaticalization theory apart from Diachronic Construction Grammar, which at this point has not been able to generate a system of testable hypotheses in quite the same way.

I have said that I view Diachronic Construction Grammar and grammaticalization theory as largely overlapping, but as not completely coextensive. There are reasons to say that grammaticalization has a narrower scope than Diachronic Construction Grammar. Specifically, there are patterns of lexicalization and lexical-semantic change that we would subsume under Diachronic Construction Grammar, but that are outside the scope of grammaticalization.

For example, there are some processes that never happen in grammaticalization, but that are common in lexical-semantic change, i.e. semantic narrowing. The English word meat used to mean "food in general". In Present-Day English it has narrowed down to mean "animal flesh". There is further the phenomenon of amelioration in semantic change. The English adjective nice meant "foolish", now it means something like "pleasant". It has acquired a more positive meaning. That is not the kind of meaning change that you see in grammaticalization.

In many definitions of grammaticalization, there are differences, but many definitions exclude word order changes, which would of course instantiate change in the constructional network. One example of this concerns the loss of English V2 constructions, another concerns changes in argument structure, specifically the diachronic increase of transitive structures in English. All of these examples suggest that the linguistic changes that grammaticalization focuses on form a subset of those that Diachronic Construction Grammar is concerned with.

However, that is not the whole story. You can also make the opposite case, arguing that some aspects of grammaticalization go beyond changes in individual form-meaning pairings, so that grammaticalization could be said to have a wider scope than Diachronic Construction Grammar. Let me give you two examples to illustrate this.

One example comes from the work of Christian Lehmann (2015), and it pertains to what he calls paradigmatization, which is the tendency of 
grammaticalizing constructions to form paradigms or to integrate into already existing paradigms. That, if you like, is a generalization about developments that affect groups of constructions. Grammatical domains like case, person, number or tense tend to recruit a small group of closed-class elements into their service, and then these elements tend to express semantic oppositions, and they tend to converge in terms of their morphosyntactic behavior. This happens in similar ways across different grammatical domains that have different formal expressions across different languages. In other words, to say that we frequently observe paradigmatization in language change is to express a meta-generalization about how groups of constructions tend to change over time. It is broader than analyzing the developmental trajectory of a single construction or group of constructions.

There is another example that comes from a very different theoretical background. Ian Roberts and Anna Roussou (2003) have developed a generative approach to grammaticalization, which is in many ways opposed to Lehmann's work. One aspect in which it runs counter to the Lehmannian view is that Roberts and Roussou view syntactic scope increase as definitional for grammaticalization. What they say is that grammaticalization involves syntactic reanalysis that assigns the grammaticalized form to a higher node in the syntactic structure.

An example for this would be the grammaticalization of lexical verbs into auxiliary verbs. When lexical verbs become auxiliaries, they are assigned to an operator position that sits up a little bit higher in the syntactic tree. Now you do not have to agree with any particular theoretical model of syntax to appreciate the generalization that is at stake. Across several different grammatical domains, across different construction types, we observe scope increase, and that will be a formal generalization that reaches across individual constructions and that expresses a more general property of grammaticalization. Both the example of paradigmatization and the example of scope increase capture generalizations across many different constructions.

All of these differences suggest that grammaticalization theory and Diachronic Construction Grammar are not quite the same, but it remains a given that grammaticalization theory has been gravitating towards a constructional perspective over recent years. For example, when we take Hopper and Traugott's definition of grammaticalization that I mentioned earlier, we see that there is an interesting difference between the 1993 edition of their textbook and the version that came out ten years later, in 2003. The 1993 version embodies what we could call the "item-based view". There the definition states that "grammaticalization is the subset of linguistic changes through which a linguistic item in certain uses becomes a grammatical item, or through which 
a grammatical item becomes more grammatical". This is the item-based view. The 2003 version has been updated to reflect the status of constructions: "the change whereby lexical items and constructions come in certain linguistic contexts to serve grammatical functions".

The shift towards a constructional view has also been commented on by Joan Bybee (2003), who has the following to say about it:

The recent literature on grammaticalization seems to agree that it is not enough to define grammaticalization as the process by which a lexical item becomes a grammatical morpheme, but rather it is important to say that this process occurs in the context of a particular construction.

To sum this up, what is reflected in the changing definitions of Hopper and Traugott and in the quote by Bybee is that there is an increasing focus on changes that affect the syntagmatic axis of language during grammaticalization. This explains in part why grammaticalization theory has been aligning with Construction Grammar.

There are, however, further differences that I find to be considerable. One of them being the fact that grammaticalization theory makes testable predictions. I have been mentioning that fact. One of these predictions concerns what's called "unidirectionality". That is the idea that changes proceed in a very constrained way that is irreversible. Let me give you a non-linguistic example for unidirectionality. This morning at breakfast I had a bowl with yogurt with a little bit of jam on top. If I stir the yogurt with a spoon, it will mix with the jam until I have a fairly homogeneous mixture. Let us say that I have been moving the spoon towards the right. If I take the spoon and turn it back to the left three times, I won't get my jam back. The mixing process is unidirectional, and grammaticalization theory holds that many processes of language change are actually like mixing yogurt with jam. They go into one direction, but not in the opposite one. Generalizations like the hypothesis of unidirectionality are one example where grammaticalization theory has a wider scope than Diachronic Construction Grammar, because the hypothesis applies to a broad range of constructions, not just a single one.

Diachronic Construction Grammar is concerned with many changes that are in fact bidirectional. For example, English gives its speakers the possibility to use verbs as nouns and nouns as verbs. There is the verb run and "I can go for a run". There is a noun butter and "I can butter a slice of bread". Another example would be analogical change. Frequently analogical change turns an irregular form into a regular one. The verb weep in English forms the past tense with an irregular form wept, but you will find it used in a regularised way where 
speakers opt for weeped. Importantly, analogical change does not always target the regular form that has the highest type frequency. Sometimes the target is a smaller class with a few highly salient members. The verb sneak is regular, but speakers started to use an irregular past tense form snuck, using an analogy with verb forms such as strike and struck, stick and stuck as salient members of this irregular category. The third example is that in lexical semantic change, semantic narrowing coexists with semantic broadening. Semantic narrowing is illustrated by the example of meat. The converse process is widening. The English noun dog referred to a specific breed of dog, now it refers to the entire species. In grammaticalization, we do not regularly see semantic narrowing, as items usually extend towards broader, more abstract meanings.

By contrast, in grammaticalization, developments are supposed to go in one direction only. This can be illustrated, for example, with the development of affixes that turn from independent words into structures that are dependent on a host structure. The English regular past tense, written as - ed, derives from a formally independent verb form with the meaning "did". Another example, the adverbial suffix -ly in friendly, derives from an independent word meaning "body" that acquired the meaning of similarity and which ultimately turned into the suffix that we are using today.

The hypothesis of unidirectionality states that independent elements lose in formal and semantic substance and turn into dependent elements, not the other way around. That is why it is interesting to pay close attention to cases that seems to go against the overall tendency. There is an example that you are perhaps aware of, namely the use of the English suffix -ish as an independent word. If I want to say that some activity took me about two hours, I can say that "It took me two hours ish", meaning about two hours. Grammaticalization scholars would see this as an anomaly. It is not supposed to happen, but every now and again it does happen. Despite these counterexamples, grammaticalization theory incorporates the unidirectionality hypothesis as a way of making predictions about unseen data.

In the framework of Lehmann, unidirectionality does not only apply to the development of suffixes out of independent words, but it actually reaches across a set of related properties of language. Lehmann identifies six separate unidirectional processes that I will briefly present.

Erosion means that as forms grammaticalize, they lose in substance and they become shorter. Condensation means that grammaticalizing forms shrink with respect to their syntactic scope. The suffix -ly used to be an independent word, but now it just forms part of an adjective. The process of paradigmatization captures that as forms grammaticalize, they integrate themselves into a group of grammatical forms with similar properties. 


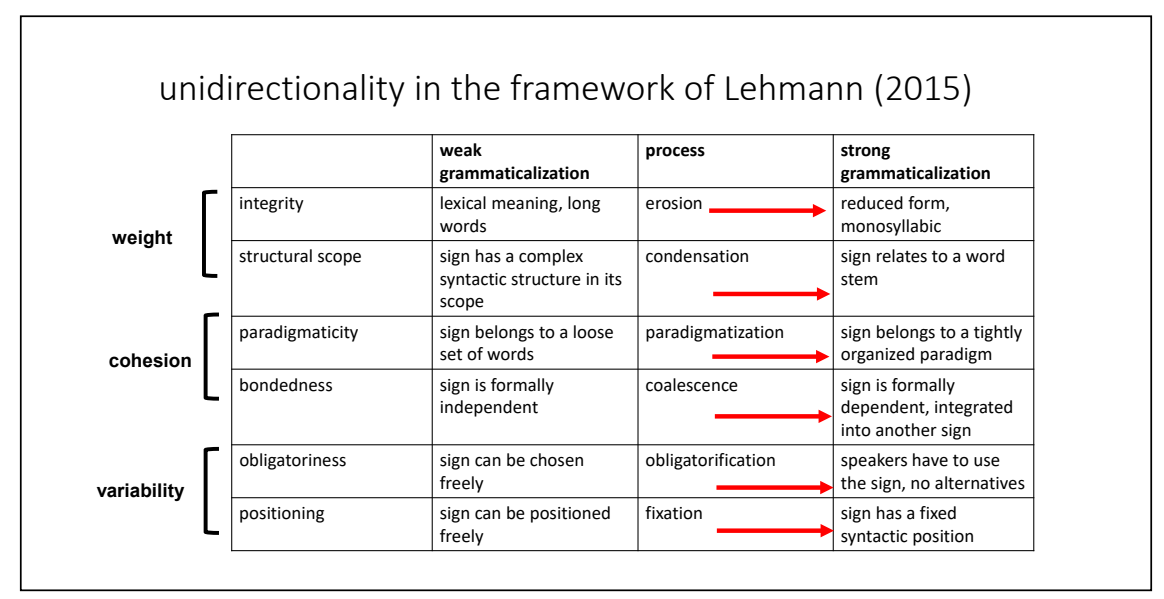

FIGURE 1

Coalescence refers to the increasing dependence of a grammaticalizing form to a host structure.

Obligatorification means that strongly grammaticalized signs have to be used as a matter of convention. For example, in languages that have articles that are definite and indefinite, the speaker has to pick one, depending on the context. The speaker no longer has the freedom to include the article or leave it out.

Finally, fixation means that as a form grammaticalizes, speakers become increasingly constrained with regard to the position in the utterance where a sign can be used.

Why am I going through all of this? My general point is that grammaticalization theory proposes this elaborate system of interlocking continua, which are tied to very specific and strong empirical predictions. We expect language change to proceed along these lines, but not in the opposite direction. Diachronic Construction Grammar, by contrast, has up to this point not been able to generate a similar set of hypotheses that could be put to the test in a systematic fashion.

To bring my juxtaposition of the two frameworks to a close, what I want you to take away is that I see the two as closely related enterprises that show substantial overlap, but that also each have characteristics that are respectively their own.

With all of this in mind, let me now outline the project of Diachronic Construction Grammar in more positive terms. I will take as my starting point the basic idea that linguistic knowledge is to be conceived of as a large structure network of form-meaning pairings. I would like to advance the view that 
Diachronic Construction Grammar is the study of changes happening in that network. Knowledge of language, from the view of Construction Grammar, is a network of constructions. Language change, from the view of construction grammar, would be change that happens in that network.

In the next part of this lecture, I want to go over four aspects of that kind of change. First, how new constructions emerge or disappear. Second, how existing constructions change in form and meaning. Third, how links in the network emerge or disappear. Fourth, how existing links in the network becomes stronger or weaker. I am going to start with the emergence of new constructions, which is undoubtedly what has captured most of the attention of researchers working in Diachronic Construction Grammar.

Elizabeth Traugott and Graeme Trousdale (2013) have created a technical term that captures the emergence of constructions. The term is "constructionalization", and it is defined in the following way:

constructionalization is the creation of form new-meaning $_{\text {new }}$ (combinations of) signs. It forms new type nodes, which have new syntax or morphology and new coded meaning, in the linguistic network of a population of speakers.

This means that a new symbolic unit is coming into being, but there is one fairly important addition, and that would be that "formal changes alone, and meaning changes alone cannot constitute constructionalization". We cannot make new symbols by adding just one part of their structure. It has to be both form and meaning. To help us understand this concept a little better, let me try to break down the definition into its component parts.

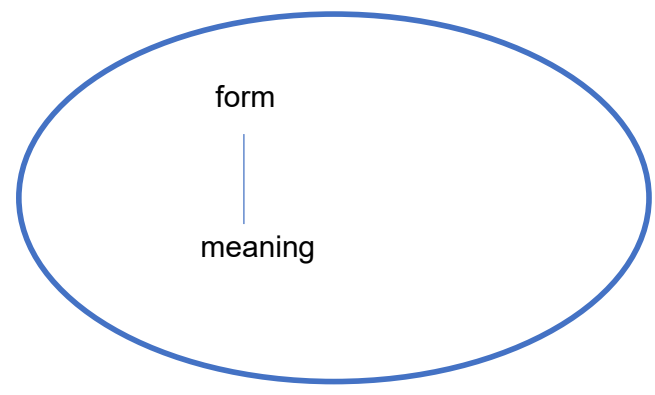

FIGURE 2

We start with a construction, a pair of form and meaning. 


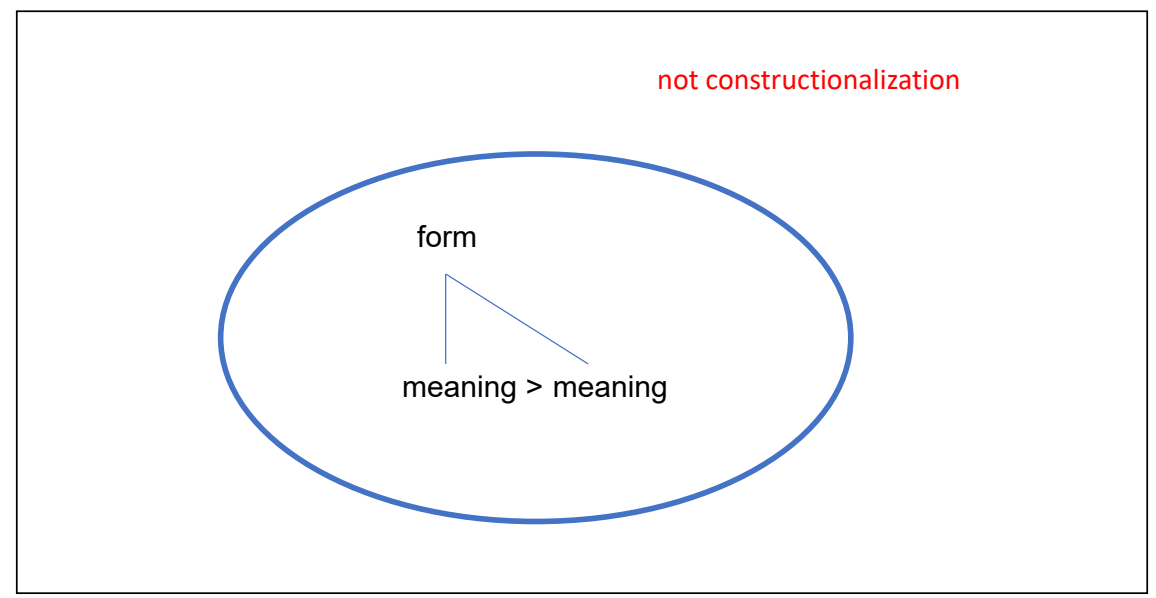

FIGURE 3

In the first step, the meaning may become extended to a second meaning, still associated with the same old form. For example, a lexical item may be extended to cover new semantic territory. An adjective such as sweet no longer refers to just to taste, but also to an emotional quality. When I say 'That was so sweet of you', we'd have a new meaning of sweet attached to the same form. According to Traugott and Trousdale, that is not constructionalization. That is a semantic change.

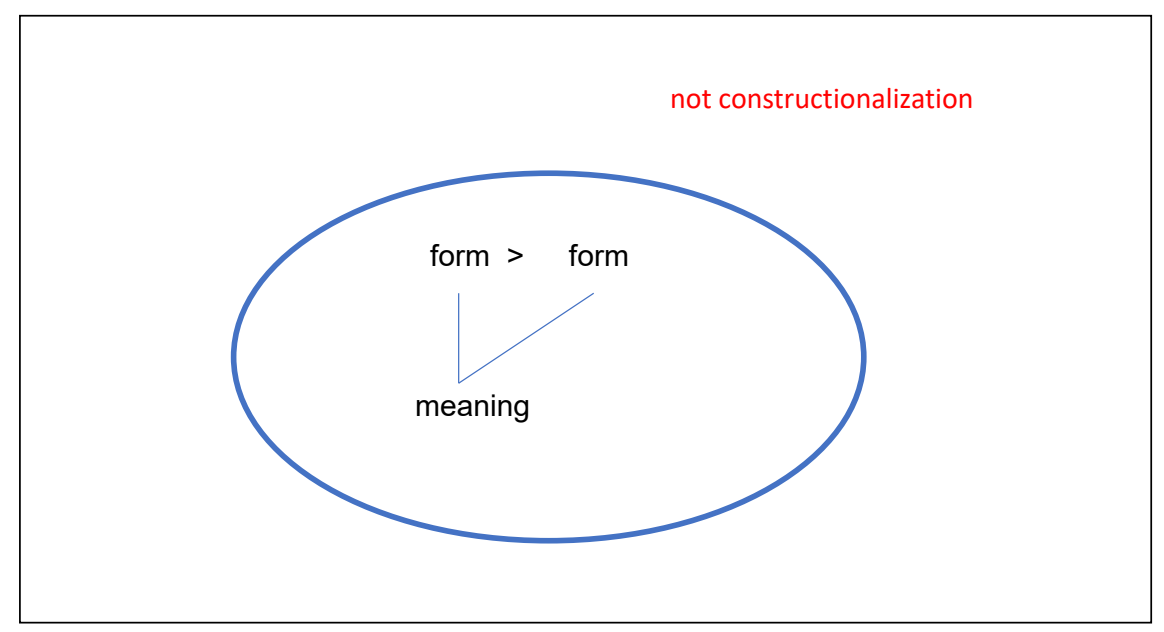

FIGURE 4

Conversely, let's say that we have a form-meaning pair, one form, one meaning, and then a new variant of the form develops. It could be a shortened pronunciation. The English word family /'fæmili/ is quite often shortened down 


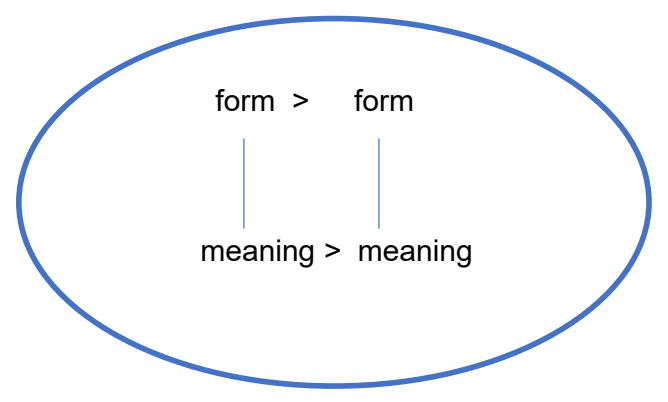

FIGURE 5

to family /'fæmli/. The first variant has three syllables, the second one has only two syllables. According to Traugott and Trousdale (2013), that would not be constructionalization.

Now suppose that we have a form-meaning pair and that pair develops in such a way that at some point a new form develops, and simultaneously, there is also a new meaning that develops. Eventually, speakers come to perceive and use the pairing of the second form and the second meaning as a form-meaning pair of its own, separate from the first form-meaning pair.

FIGURE 6 
That case represents what Traugott and Trousdale (2013) would call constructionalization, the emergence of a new form-meaning pair in the network of constructions that constitutes a speaker's knowledge of the language.

There have been proposals to the effect that this process, constructionalization, should be equated with grammaticalization. Dirk Noël (2007) was one of the earliest researchers to talk about Diachronic Construction Grammar as a theoretical framework in its own right. What he says is this:

In Construction Grammar constructions are by definition grammatical, so that the historical emergence of constructions amounts to becoming part of the grammar, and what better term to denote this than grammaticalization.

I am afraid that I disagree with this proposal, since I find that it rests on a somewhat unfortunate interpretation of the term "grammar". What is true is that Construction Grammar as a theory attempts to model speaker's knowledge of the language in total. In that sense, grammar could be a term that stands for everything that a speaker knows, i.e. all of a speaker's knowledge. Still, I do not think it is helpful to say that in Construction Grammar, constructions are by definition grammatical. Not all constructions are grammatical. That term should be reserved for constructions that are advanced on the clines that grammaticalization research has worked out. Articles are grammatical because they are highly dependent on a host structure and because their use is obligatory. Relative clauses are grammatical because they are syntactically complex and convey a very schematic kind of meaning. Lexical words like bicycle or lecture or bottle are constructions, but they are not grammatical constructions. They're lexical constructions.

In their 2013 book on constructionalization, Traugott and Trousdale make a distinction between two different types of constructionalization, one which they call lexical or contentful constructionalization, and another type that they call grammatical or procedural constructionalization. Lexical constructionalization refers to the coinage of new lexical items, such as photobomb, twitterverse or Brexit. Lexical constructionalization typically starts with the instantaneous creation of a new form which is then gradually propagated in the speech community and which conventionalizes through usage over time.

By contrast, grammatical constructionalization concerns the emergence of new grammatical constructions. In English, examples would include the emergence of the passive with the verb get, as in "It is ok as long as you do not get caught", or the double-is construction, "The problem is is we are out of money", or what's been called contrastive reduplication, "Does he like me or does he like-like 
me?" Grammatical constructionalization bears all the features of grammaticalization that I have described earlier. The constructions involve grammatical dependencies. They encode abstract meanings. They arrange themselves into paradigms.

Traugott and Trousdale (2013) identify three aspects of constructionalization that they view as central, and that allow them to distinguish between lexical constructionalization and grammatical constructionalization. These three aspects concern the compositionality of a construction, the schematicity of a construction and the productivity of a construction. For example, when a new passive construction such as the get-passive undergoes grammatical constructionalization, there is a decrease in compositionality, so the verb get no longer means just "get". At the same time, there is an increase in schematicity. The overall construction is not just get, but it is rather get plus a slot for a verb in the infinitive. There is an increase in productivity, meaning that as time goes on, we find more and more lexical verbs that enter the past participle slot, that are used with get in order to form an instance of the get-passive. For grammatical or procedural constructionalization, we have increases in schematicity and productivity and a decrease in compositionality.

For lexical/contentful constructionalization, we have a different profile. Specifically, we have decreases for all three aspects, i.e. for compositionality, schematicity and productivity. Let's take the example of Brexit. Brexit is a blend from Britain and exit, but it encodes a very specific meaning of "Britain's exit from the European Union". There is no strict compositionality, and there is no schematicity, as the meaning of Brexit is quite specific.

Traugott and Trousdale (2013) use these notions as a way of capturing the broad difference between grammar and lexis, which is a distinction that I think is important, even if it is not crisp and categorical, but rather non-discrete and gradual. There are elements that are clearly lexical, like dog or friendly, which are contentful and which have specific meaning. There are grammatical elements such as determiners, pronouns, auxiliaries or the ditransitive construction, which clearly convey procedural meaning and which are discursively secondary.

Then, there are lots of in-between cases, for example, newly grammaticalized auxiliaries such as the verb help in "help solve the problem", and other examples that are not quite grammaticalized, but not quite lexical either. On this view, grammatical constructions convey a very specific type of meaning that can be called procedural. In the words of Traugott and Trousdale (2013), procedural meaning can be defined as follows: "A grammatical sign cues how the speaker conceptualizes relationships between referents within the clause". This captures notions such as subject and object and their functions within 
a clause-level predicate construction. I have added a second definition here by Holger Diessel (2019), who defines the term in a slightly different way: "Grammatical constructions provide processing instructions that guide listeners' semantic interpretation of lexical expressions". This means that how our interpretation of a lexical item depends on the grammatical context. This actually brings us back to the principle of coercion that I mentioned earlier this morning. When I say "Three beers, please", the plural construction guides the listeners' interpretation of the word beer. Putting it all together, we can circumscribe procedural meaning as meaning that corresponds to questions like Who did what to whom?, When did it happen?, How sure are we that it happened?, and What part of the event are we talking about?

In all of this, you recognize bits and pieces of basic idea \#3, Langacker's (2005) observation that constructions vary in terms of their degrees of complexity and schematicity. Procedural meaning is notably more schematic than the meanings that are associated with lexical material. Grammatical constructionalization in the sense of Traugott and Trousdale (2013) is concerned with the emergence of constructions in more abstract areas of linguistic structure that accommodate category schemas and constructional schemas. While this gives us a basic understanding of grammatical constructionalization, there is one more distinction that I need to introduce in this context, and that distinction concerns two different types of grammaticalization.

So far, I have talked about grammaticalization in terms that presented it as a tendency towards increasingly compact linguistic structures from discourse to syntax to morphology, and eventually to zero. This is commonly called the view of grammaticalization as reduction. Grammaticalizing forms lose their autonomy, their complexity, their syntactic freedom and their phonetic substance. This works very well for phenomena such as the creation of morphological affixes out of formerly independent words, or for the reduction of the be going to construction into gonna.

Grammaticalization as reduction is essentially the view of grammaticalization that is presented by Christian Lehmann, with its six unidirectional processes that lead to increasingly compact and compressed structures. All of that works very well for the structures it has been intended to deal with. But there are other phenomena that we might want to call grammaticalization, but that do not fit into this view.

There is a second type of grammaticalization running counter to the first one, and that type can be described in terms of expansion. The gist of the matter is that not all grammaticalizing constructions become more fixed and integrated, lose in semantic substance, and decrease in syntactic scope. Some constructions show the exact opposite behavior. There are three phenomena 
that I briefly want to talk about, namely host-class expansion, the increase of syntactic scope, and semantic expansion.

The term host-class expansion signifies that a grammaticalizing construction over time increases its range of hosts, that is, the range of elements that cooccur with the construction. Let me start with the English way-construction, as illustrated by He made his way through the room or He elbowed his way out of the subway. This construction has historically come to be used with an evergreater range of verbs. At first, it used to be restricted to verbs that relate to the laborious creation of a path. Now you can cheat your way into law school and sing your way into the charts. The construction become more open to different kinds of verbal predicates.

Another example are noun-participle compounds like doctor-recommended, child-tested or chocolate-covered. If we look at that kind of construction diachronically, we find that the number of participles occurring in that construction has been on the increase. Host-class expansion can also be observed on the syntactic level. The example that I can give you here are it-clefts in English, which used to be restricted to examples in which the focus phrase was a noun phrase: It was the butler who killed them. In present-day English, we have a number of other elements that can occur as the focus phrase, for example, prepositional phrases like It is in May that she's coming or ing-clauses, as in It is eating broccoli that Ijust can't bring myself to do.

Increase of syntactic scope is what we observe when a grammaticalizing construction comes to modify increasingly larger syntactic units. Lehmann predicts that the exact opposite should happen. Grammaticalizing units should decrease progressively in their syntactic scope, but we see the opposite with discourse markers that are based on adverbs, as for instance the word actually. Actually can be an adverb. I can ask Is this measure actually necessary, and in that sentence, actually has an adjective phrase in its scope. In a sentence like They actually wanted to talk to you, actually has a verb phrase in its scope. In its use as a discourse marker or sentence adverbial, it has an entire utterance in its scope. This would be the case for examples such as Actually, this does not seem like a good idea. Actually has progressively increased the size of the syntactic contexts over which it has scope.

The same goes for the clause connector as long as, which used to be just a modifier for a noun phrase, as in We will do this for as long as a year. It is expanded into contexts where it has scope over a clause: As long as you keep it frozen, it will stay edible.

The last phenomenon that I want to talk about with regard to grammaticalization as expansion is semantic expansion. Over the course of time, grammaticalizing constructions come to be used with an ever-greater range of 
meanings. This applies to, for instance, the development of grammatical auxiliaries. Let's take the English modal auxiliary may, which is used in deontic and epistemic meanings. The example You may now kiss the bride expresses permission and thus deontic modality. That may have been a mistake expresses a logical possibility. May has expanded semantically over time.

The same goes for the example of as long as that I mentioned a minute ago. Originally, this refers to a time span. The example as long as you keep it frozen refers to the time during which you keep something frozen. When I say As long as you have the money, you can come in, I do not refer to a period of time, but rather I refer to the condition that you have the money. The shift from temporal to conditional meaning instantiates semantic expansion.

When we consider how Traugott and Trousdale define grammatical constructionalization, it seems that their view aligns closely with the view of grammaticalization as expansion, rather than Lehmann's view of grammaticalization as reduction. Let us look at a few concrete examples of grammatical constructionalization and their developments.

\section{increase in productivity}

- what's usually meant: type frequency

- participle types in noun-participle compounding (doctor-recommended) in COHA

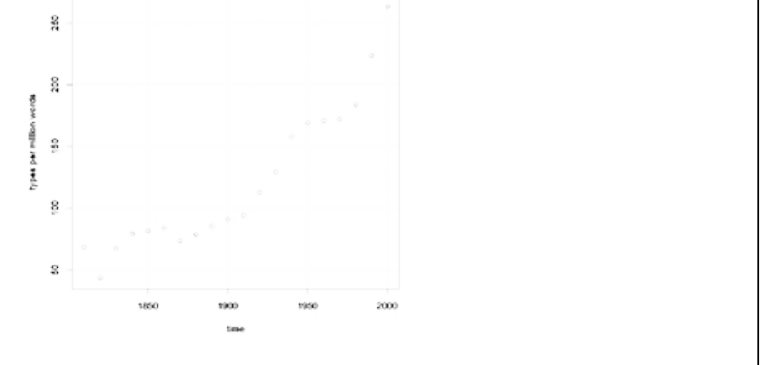

FIGURE 7

Let's start with the increase in productivity that happens during grammatical constructionalization. When Traugott and Trousdale (2013) discuss increases in productivity, they refer to increases in the type frequency of a construction. How many different lexical items are found in usage with a given construction? On this slide, you can see a graph with an increasing curve over time. That curve represents the growing number of participle types that are found in the English noun-participle compounding construction, as for example doctor-recommended or kid-tested. As time goes on, more and more different 
participle types are included in instances of this construction, and this would represent an increase in productivity.

When Traugott and Trousdale (2013) discuss increases in schematicity, what they have in mind is that a construction acquires a meaning that is increasingly abstract. In the grammaticalization literature, this process goes by the name of semantic bleaching. There are many examples of this. For example, the English be going to future construction no longer necessarily encodes motion. We find it being used with inanimate subjects in utterances such as Inflation is going to be a problem. The example does neither convey intention nor movement. The construction has become more schematic in its meaning. Also, the example of as long as applies here, as it no longer just encodes time, but also a condition, as in as long as you have the money.

Decreases in compositionality mean that the meaning of constructions becomes less and less transparent. In other words, the idiosyncrasies or unpredictable characteristics of the construction are on the rise. The development starts with broadly compositional meanings. For example, in the expression $a$ bit of, the example He gave me a bit of bread refers to a piece of bread that corresponds to something that you can bite off, a small chunk. When I say Ineed a bit of sleep, that is a short period, which is not exactly the same thing as a bitesized object. When I say That is a bit of a secret, is that a limited part of a secret? Is that only secret-like in some ways? You see how the compositionality of the expression $a$ bit of reduces over time and gives way to a more holistic meaning.

The same applies to the English have-perfect, which combines the verb have and a past participle. Early uses of the construction are used to express actual possession. The example that you see often used in this context is I have the enemy bound, which denotes that the enemy has been won over and is in the state of being tied up. When I say I have read the book, I still presumably have that book in my possession somewhere. I may have given it away, but it was in my possession at some point. But when I say I have slept well, is that period of sleep in my possession? Was it in my possession when I was actually asleep? That is debatable. What is clear, however, is that the compositionality of the have-perfect has over time become less compositional.

Grammatical constructionalization, according to Traugott and Trousdale (2013), is a process that involves an increase in productivity, an increase in schematicity, and a decrease in compositionality. Constructionalization would be the moment when all of these developments come together, and a new node appears in the construct-i-con. This node has to instantiate a new formmeaning pair, such that both the form and the meaning are recognized as new by speakers of the speech community. This brings up the question of how we should think about changes that happen to an existing form-meaning pair. For 
instance, what about semantic expansion without formal change or phonological reduction without semantic change?

Dirk Noël (2007) pointed this out a long while ago in a quote that may have prompted Traugott and Trousdale to coin the term constructionalization:

What Diachronic Construction Grammar has so far failed to do, however, is draw an explicit distinction between the initial formation of a construction, that is a primary association of a meaning with a particular (morpho)syntactic configuration, and the possible subsequent change of a construction into a more grammatical one.

In the grammaticalization literature, there is a distinction between primary grammaticalization on the one hand, which corresponds to Noël's formulation of the initial formation of a construction, and secondary grammaticalization, which corresponds to the subsequent change of construction into a more grammatical one. Traugott and Trousdale's constructionalization covers the initial creation, but what about subsequent changes?

This is something that I have been thinking about. I have been using the term "constructional change" in order to capture all the processes that can affect existing constructions, using the following definition:

Constructional change selectively seizes a conventionalized formmeaning pair of language, altering it in terms of its form, its function, any aspect of its frequency, its distribution in the linguistic community, or any combination of these.

This definition is intentionally very broad, since it is meant to engage with all aspects of constructions. The most important aspect of the definition is actually the very first part, namely that constructional change is selective about what it affects. It selectively seizes a conventionalized form-meaning pair. This means that constructional change is not a system-wide change, or a change that affects multiple constructions at the same time. It is really a very local kind of change, and the types of change that may affect single form-meaning pairs. They are, however, of a more general nature, and you're all very familiar with them.

There are changes in form, such as phonological reduction of I am going to to I am gonna and further to even more reduced forms.

Changes in form also concern the obligatorification of a particular part of a construction. Here I come back to the English way-construction, which has historically come to include an obligatory path or goal constituent. That wasn't 
the case all along. Early on, we find examples like "The legions speed their headlong way", without a specification of where they are actually going. As time goes on, the relative frequency of examples with a goal or path constituent, they steadily increase in relative frequency until we approximate a hundred percent.

Changes in form also subsume what I talked about in terms of host-class expansion. Here again is the example of the $i t$-clefts who expand from noun phrases to prepositional phrases to adverbial phrases and ing-clauses, and you find even other constituent types. Changes in form is one type of change that can be subsumed under constructional change.

The same is true of changes in meaning, which I do not need to exemplify in much detail. Let me just come back to the adverb actually, which can be used as either an adverbial stating factuality, He actually handed in his thesis last week, or as a discourse marker in examples such as Actually, he handed in his thesis last week.

Changes in meaning are ubiquitous in grammaticalization, from lexical meaning to more abstract grammatical meanings. Since I have mentioned the term, let me give you an example of secondary grammaticalization. One way in which secondary grammaticalization can manifest itself is semantic change in grammatical elements such as the sentence connector since. Originally an expression of a temporal relation, since expands semantically to express a the meaning of causality, as in Since I have a German passport, I do not need a visa for Poland. That example does not make a statement about a temporal sequence of events. I have had this passport all my life, I am not referring to situation of before and after.

As for changes in frequency, what you find being discussed most often in the literature are changes in text frequency. Some forms fall out of fashion, and speakers use them less and less. Other forms come into a fashion and increase in frequency. That is one aspect, but there are other types of frequencies that are also worthy of investigation. I have mentioned the increase in type frequency of the noun-participle construction in English, which is illustrated by forms such as work-related. This construction type has enjoyed a tremendous success in terms of increasing type frequency.

Changes in frequency further subsume changes in the relative frequency of constructional variants, that is, competing or alternative constructions, such as the $s$-genitive and the of-genitive in English. Historically, it can be shown that $s$-genitives have changed in their relative frequency profile with regard to possessors that are inanimate. One hallmark of the $s$-genitives is that they typically feature an animate possessor, as in John's friends. However, in present-day English, something like yesterday's events is a possible way of expressing that 
something happened yesterday. That wasn't always possible, nowadays it is. Another example involves the ditransitive construction and the animacy of its recipient role. In the example Let's give the turkey five more minutes, the turkey won't receive those five minutes, as it is not an animate recipient. It didn't use to be the case that ditransitive could incorporate recipients that are in fact inanimate.

As for the last type of frequency change, when we investigate constructions and how they change, a crucial aspect is change in the social distribution of a construction. Who is using a particular construction? Does a construction spread out from a small group of speakers to a broader range of age brackets and a wider geographical distribution? The infamous be like quotative in English, I was like, what's that all about, started as a construction that only a particular subset of speakers would use, but it spread to larger and larger communities. A term of address like dude instantiates gendered language use that is typical for male to male speech. It spread to female speakers, who prefer it in same-gender conversations.

Typically, constructional change alters multiple aspects of a construction at the same time. What I have said so far addresses two concerns of Diachronic Construction Grammar, namely how constructions emerge and how they change. Knowledge of language, according to Construction Grammar, is a network of constructions with form-meaning pairings that are mutually connected in various ways. What I have not covered up to this point, but what will be a major focus of what I have to say in later lectures is how we can think about connections between constructions.

In the last couple of minutes for this lecture, let me talk about connectivity change. A lot can change in the network when new links emerge or old links disappear. I would like to discuss two examples. First, we can think about meaning extensions as connectivity change. In meaning extension, such as the meaning of hopefully or the meaning of actually that I have been talking about, an existing form is linked to a new meaning, which may already exist, albeit linked to a different lexical item.

Second, another type of connectivity change would involve a newly emerging construction which would be linked to a construction that is functionally equivalent. Speakers identify the new construction as an alternative, that is, as a possible competitor, or a possible alternative, to an established construction. I have mentioned the get-passive. When this construction came into being, it would have been connected in speaker's minds to the already existing $b e$ passive. Speakers noticed it as a new way of expressing the same idea. This is something we could call "synonym linkage". When a new element comes into a language, it is connected to existing elements that express related ideas. 


\section{existing links become stronger or weaker}

\section{connectivity change}

- change in mutual association strength

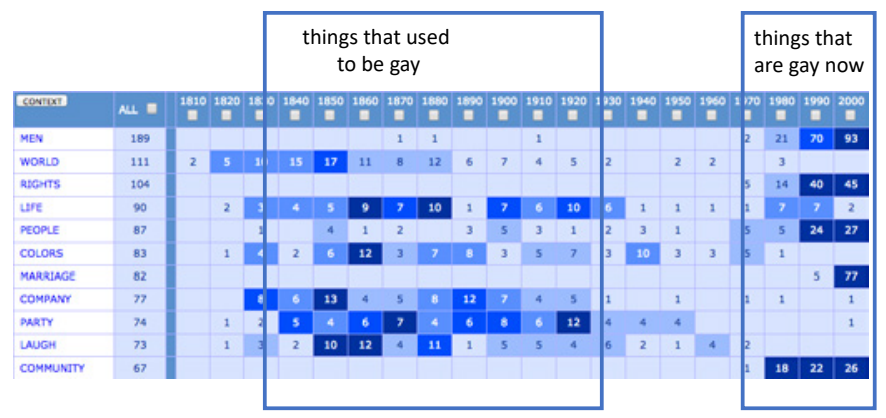

FIGURE 8

\section{existing links become stronger or weaker}

\section{connectivity change}

- change in mutual association strength

- I dislike ...

- ... to do the dishes (to-infinitive)

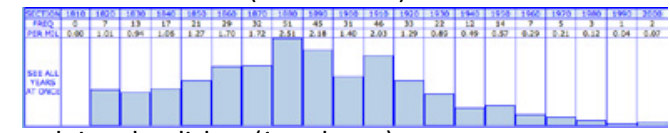

-... doing the dishes (ing-clause)

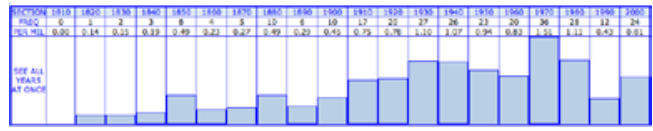

FIGURE 9

Emerging or disappearing links give us interesting material to work with, but that is not the whole story. Much more typically perhaps, what happens is that existing links become stronger or weaker. What you see on this slide here is a display of words that frequently co-occur with the adjective gay in the Corpus of Historical American English. The darker the shade of the cell in the table, the more frequent the collocation pattern. You see that some collocations 
were highly entrenched in the 19th century and a very different set of collocations are entrenched in the late 2oth century. Early collocations were expressions such as gay colors, a gay laugh and a gay party, those are joyful events. Today we talk about gay men, gay rights and the gay community. This reflects the semantic change that the adjective gay has undergone. As gay changed semantically, its connections changed as well, to the point that there are now two form-meaning pairings.

This not only happens in semantics but also in syntax. This slide shows another data example from the Corpus of Historical American English. This time it is the complement-taking behavior of the verb dislike. In Current American English, dislike primarily takes ing-clauses as complements, as in I dislike doing the dishes. This wasn't always the case. As late as the early 2oth century, speakers used dislike with to-infinitives, as in I dislike to do the dishes. In Present-day English, this connection between dislike and the to-infinitive has all but disappeared from the grammar. An existing link has become much weaker, and you can see in the smooth decline of frequencies that this must have happened gradually.

Another type of connectivity change or changing strength in links would be concerned with form-meaning links in polysemous constructions. Polysemous forms are linked with several interrelated meanings, and these links vary in strength. For example, the English verb to miss is connected to several meanings. It can have the meaning of "longing", as in I miss my grandma and that meaning occurs with a certain frequency. Another meaning is "to fail to reach in time", as in I missed my train. There is also the meaning of "not being in possession of" as in He was missing a front tooth. The words in the context of miss disambiguate those meanings. But the links between miss itself and these different meanings vary in strength, and that can be operationalized in terms of how frequent a verb is used in a certain sense.

I am coming to a close here. What I have talked about are mainly the issues of constructionalization, i.e. how new nodes emerge in the constructional network and the opposition of lexical constructionalization and grammatical constructionalization as Traugott and Trousdale conceive of it. I have talked about constructional change, the behavior that existing nodes in the network can exhibit with regard to their form-meaning frequency or distribution in the community of speakers. I have drawn your attention to connectivity changes, the emergence or disappearance of links in the constructional network and what this means for things like meaning extension or other types of semantic development. Lastly, I have talked about changes in connection strength, the associative links between two constructions that can become stronger or weaker as time goes on. With that, I would like to come to a close and thank you for your attention. 